\title{
Análise microbiológica de saladas em pote prontas para consumo
}

\section{Ana Caroline Feitoza de Carvalho}

Possui graduação em Nutrição pelo Centro Universitário de Volta Redonda RJ (2018). Atualmente inserida no programa de residência de Atenção ao Câncer, no Hospital de Amor, Barretos - SP. Pós graduanda em Terapia Nutricional, na Faculdade de Ciências da Saúde, Barretos - SP.

\section{Margareth Lopes Galvão Saron}

Doutora pela Faculdade de Ciências Médicas da Universidade Estadual de Campinas FCM/UNICAMP. Mestre pela Faculdade de Engenharia de Alimentos da Universidade Estadual de Campinas FEA/UNICAMP e possui graduação em Nutrição.

\section{Cyntia Ferreira de Oliveira}

Pós-doutorado (2013) no Instituto Nacional de Câncer e doutorado em Oncologia pelo Instituto Nacional de Câncer (2011). Mestrado em Ciência de Alimentos pela Universidade Federal do Rio de Janeiro (2005) e possui graduação em Nutrição pela Universidade do Estado do Rio de Janeiro (2002),

\section{Aline Cristina Teixeira Mallet}

Graduação em Nutrição pela Universidade do Rio de Janeiro - UniRio (2002), Especialização em Controle de Qualidade dos Alimentos (2004) pelo Universidade Federal de Lavras, Mestrado em Ciência dos Alimentos (2007) e Doutorado (2011) pela Universidade Federal de Lavras. Pós-doutorado em Biotecnologia (2012). 


\section{Resumo}

Devido à alta demanda na busca de hábitos mais saudáveis e mudança no estilo de vida da população, segundo o ministério de saúde do Brasil, os produtos alimentares minimante processados ganharam seus lugares no mercado. São considerados minimamente processados, os alimentos que sofreram algum tipo de alteração física ou química, os tornando prontos para o consumo ou preparo. Devido ao alto grau de manuseio desses alimentos e às suas próprias características orgânicas, a possibilidade de contaminação é alta, podendo afetar a saúde da população. A ANVISA estabeleceu, através da RDC nº12 de 02 de Janeiro de 2001, os procedimentos para o controle microbiológico para esses produtos. Com o objetivo de analisar microbiologicamente, foram coletadas cinco amostras de saladas em pote prontas para o consumo de diferentes produtores e realizadas análises para presença de Coliformes termotolerantes, Salmonella spp. e Staphylococcus coagulase positiva.

Palavras-chave: Análise Microbiológica. Contaminação de Alimentos. Enterobactérias.

\section{Abstract}

Due to the demand for healthy habits and changes in people's way of life, according to Brazilian Health Ministry, minimally processed food products made their places in the market. It is considered minimally processed, food that suffered some kind of physical or chemical modification, which made it ready to consume or prepare. Because of the high degree of handling of these food and their own organic characteristics, contamination chances are high and it may affect consumers' health. ANVISA establish, through RDC no12 on January 2nd 2001, the microbiological control procedures for these products. Aiming to analyze microbiologically, Five samples of salads in containers ready for consumption from different suppliers were collected and the presence of thermotolerant coliforms, Salmonella spp. and Staphylococcus was analyzed.

Key-words: Microbiologically analysis; Food contamination; Enterobacteria. 


\section{Introdução}

De acordo com Ministério da Saúde do Brasil (2014), com a recente mudança do estilo de vida e dos hábitos alimentares que a população brasileira vem vivenciando, cada vez mais há uma procura por praticidade. $\mathrm{Na}$ alimentação, há uma preocupação crescente em relação a exercer hábitos mais saudáveis. E, com isso, tanto o consumo quanto o mercado de produtos saudáveis e práticos estão aumentando (SOUZA, 2001).

Nesse sentido, o mercado de produtos minimamente processados teve sua ascensão nos últimos anos. Alimentos minimamente processados (AMP) são aqueles in natura os quais foram submetidos a pequenas alterações como limpeza, embalagem, pasteurização, secagem, moagem, fermentação, entre outros processos, que tornam os produtos finais prontos para consumo ou preparo (BRASIL, 2014).

Além dos aspectos de conveniência e praticidade, devem apresentar qualidade higiênico-sanitária e manter as características sensoriais de sua forma original in natura (SILVA, 2008).

Não só devido ao manuseio dos alimentos minimamente processados, mas também às suas características físicas e químicas, esses produtos podem sofrer diferentes tipos de contaminação, oferecendo risco à saúde da população (FRODER et al., 2007).

De acordo com Paula (2010), as doenças causadas pela contaminação dos alimentos têm sido caso de preocupação para saúde pública, por ter crescido bastante os casos de infecção alimentar. Entre os microrganismos patógenos que podem ser encontrados em frutas e hortaliças frescas estão a Salmonella, Listeria monocytogenes, Shigella, Escherichia coli, Bacillus Cereus, Staphylococcus aureus, entre outros.

Segundo a Resolução da Diretoria Colegiada (RDC) no 12 de 02 de Janeiro de 2001, da Agência Nacional de Vigilância Sanitária, o controle microbiológico dos minimamente processados se dá pelas pesquisas de Salmonella e Coliformes termotolerantes, quando estes estão crus. Quando cozidos, acrescenta-se a pesquisa de Staphylococcus coagulase positiva.

Com base nos dados informados, o presente trabalho teve como objetivo analisar microbiologicamente amostras de saladas em pote comercializadas no município de Volta Redonda no estado do Rio de Janeiro. 


\section{Fundamentação Teórica}

\section{OBTENÇÃO DAS AMOSTRAS}

Foram coletadas amostras de saladas em pote, em sua própria embalagem, em diferentes tipos de comércios da cidade de Volta Redonda, no interior do estado do Rio de Janeiro. Ademais, foram escolhidas saladas no pote com composição alimentar semelhante, tendo como principais componentes folhosos, proteína (frango), batata doce, cenoura crua ralada, brócolis e milho. As mesmas foram imediatamente colocadas em bolsa térmica contendo gelo, para que não perdessem suas características sensoriais, obtidas no ato da coleta e conduzidas ao laboratório de Microbiologia de Alimentos do Centro Universitário de Volta Redonda (UniFOA), para as devidas análises microbiológicas.

\section{Preparação das amostras}

As amostras, num total de 5 unidades, foram trituradas separadamente em liquidificador devidamente esterilizado até a completa homogeneização. A retirada das amostras foi realizada de maneira asséptica, sendo as mesmas transferidas para frascos estéreis para posterior utilização.

\section{Determinação de Coliformes}

\section{Teste presuntivo}

Foram retiradas assepticamente alíquotas de $1 \mathrm{~mL}$ das amostras e diluídas em 9 $\mathrm{mL}$ de água peptonada $0,1 \%$ em séries de tubos, transferindo-as em alíquotas de $1 \mathrm{~mL}$ das três diluições para séries de três tubos $\left(10^{-1}, 10^{-2}, 10^{-3}\right)$, contendo Caldo Lauril Sulfato Triptose (LST) e incubadas em estufa a $37^{\circ} \mathrm{C} / 48 \mathrm{~h}$. Foram considerados positivos os tubos com produção de gás nos tubos de Durham (presença de bolhas).

\section{Coliformes totais}

A partir de cada tubo positivo de Caldo LST, transferiu-se uma alçada para tubos de Caldo Bile Verde Brilhante (VB), previamente identificado com a diluição 
correspondente. Foram incubados em estufa a $37^{\circ} \mathrm{C} / 48 \mathrm{~h}$. Foram considerados positivos os tubos com produção de gás no tubo de Durham. Verificou-se na tabela de número mais provável (NMP) o número correspondente e o resultado foi expresso em NMP de Coliformes totais/mL.

\section{Coliformes termotolerantes}

A partir de cada tubo de caldo LST positivo, transferiu-se uma alçada para um tubo de caldo EC (Caldo Escherichia coli) previamente identificado com a diluição correspondente. Incubou-se em banho-maria a $45^{\circ} \mathrm{C} / 24 \mathrm{~h}$. Foram considerados positivos os tubos com produção de gás no interior dos tubos de Durham. Verificou-se na tabela de NMP o número correspondente e expressou-se o resultado em NMP de Coliformes termotolerantes ou a $45^{\circ} \mathrm{C} / \mathrm{mL}$ (SILVA e JUNQUEIRA, 2007).

\section{Salmonella spp.}

Retirou-se assepticamente uma porção de $25 \mathrm{~g}$ da amostra adicionando-a em $225 \mathrm{~mL}$ de água peptonada tamponada. Posteriormente, a amostra foi incubada a $37^{\circ} \mathrm{C}$ por 24 horas (fase de pré-enriquecimento). Na sequência, realizou-se a etapa do enriquecimento seletivo, em que se transferiu $1 \mathrm{~mL}$ desta diluição para um tubo de ensaio contendo $10 \mathrm{ml}$ de Caldo Tetrationato e $1 \mathrm{~mL}$ transferido para um tubo contendo Caldo Rapapport, ambos incubados a $37^{\circ} \mathrm{C}$ por 24 horas. A partir dos tubos dos caldos anteriores da fase de enriquecimento seletivo, foi retirada uma alçada e a inoculou em duas placas de Petri, contendo o meio Hecktoen entérico $(\mathrm{He})$. Estas foram incubadas a $35^{\circ} \mathrm{C}$ por 24 horas. Procedido esse período, foi feita a confirmação da presença da Salmonella e as devidas amostras foram encaminhadas para a realização de provas bioquímicas confirmatórias (SILVA e JUNQUEIRA, 2007).

\section{Staphylococcus coagulase positiva}

A metodologia instituída para a pesquisa de Staphylococcus coagulase positiva foi a Contagem Direta em Placas. Partindo das diluições $10^{-1}$, $10^{-2}$ e $10^{-3}$, com o auxílio de uma pipeta esterilizada, foi transferido $0,1 \mathrm{~mL}$ de cada diluição para placas de Petri contendo Ágar Baird-Parker (BP) e depois espalhou-se o inóculo por toda a superfície do Ágar BP, utilizando-se a técnica de semeadura em superfície ou Spread plate. As 
placas foram incubadas, de forma invertida, em estufa a $35^{\circ} \mathrm{C}$ por 24 horas. Posteriormente, foram selecionadas para contagem as placas que continham entre $20 \mathrm{e}$ 200 colônias típicas. As colônias típicas (negras, brilhantes, com anel opaco, rodeado por um halo claro transparente, destacando-se sobre a opacidade do meio) foram contadas para cálculo do número de unidades formadoras de colônias (UFC) por grama do alimento. Três colônias típicas isoladas de cada placa foram repicadas para tubos contendo Caldo Infusão Cérebro-Coração (Caldo BHI). Emulsionou-se a massa de células com o caldo e foi transferida uma alçada para um tubo com Ágar-Tripticase de Soja (Ágar TSA) inclinado. Ambos os meios foram incubados a $35^{\circ} \mathrm{C}$ durante 24 horas. A partir do subcultivo crescido no Caldo BHI foi realizada a prova bioquímica de Coagulase (SILVA e JUNQUEIRA, 2007).

\section{RESULTADOS E DISCUSSÃO}

$\mathrm{Na}$ Tabela 1, encontram-se expressos os resultados das amostras de saladas em pote em relação à presença de Coliformes totais e termotolerantes, de acordo com o método de contagem de Número Mais Provável por grama de alimento (NMP/g).

Tabela 1. Resultado das análises para Coliformes totais e termotolerantes em saladas de potes

AMOSTRAS Coliformes totais (NMP/g) Coliformes termotolerantes (NMP/g)

\begin{tabular}{ccc}
\hline A & $2,1 \times 10^{3}$ & $2,8 \times 10^{2}$ \\
B & $3,5 \times 10^{2}$ & 0 \\
C & $4,6 \times 10^{3}$ & $1,5 \times 10^{3}$ \\
D & $1,5 \times 10^{3}$ & $2,8 \times 10^{2}$ \\
E & $1,1 \times 10^{4}$ & $2,1 \times 10^{2}$ \\
\hline
\end{tabular}

Fonte: Autores (2018)

Todas as amostras apresentaram contagem para Coliformes totais. Quanto às análises de Coliformes termotolerantes, levando-se em consideração a RDC 12 de 2001 da ANVISA, que estabelece o limite de contagem expressas em NMP/g de $10^{2}$, pode-se 
observar na tabela 1 que, com exceção da $\mathrm{B}$, todas as amostras analisadas estão em desacordo com os padrões aceitáveis.

O grupo dos Coliformes totais é composto por bactérias da família Enterobacteriaceae, capazes de fermentar a lactose com produção de gás, quando incubados a $35-37^{\circ} \mathrm{C}$, por 48 horas. Já os Coliformes termotolerantes e E. coli fazem parte de um grupo de bactérias pertencentes aos Coliformes totais que possuem a capacidade de continuar fermentando lactose com produção de gás em $24 \mathrm{~h}$ quando incubados a $44-45,5^{\circ} \mathrm{C}$.

Mallet et al. (2017) verificaram em seu trabalho que 33\% das amostras de saladas analisadas encontravam-se fora dos limites preconizados, não estando aptas à comercialização e, consequentemente, ao consumo humano. Resultado este que se assemelha ao do presente estudo.

Corroborando com esses achados, Maciel et al. (2017), apontaram que sua pesquisa também apresentou resultados acima do permitido para a presença de Coliformes totais e termotolerantes nas amostras de saladas coletadas de dois diferentes restaurantes.

Entretanto, Fagiani (2017), em seu estudo, pode observar que a maioria das amostras de saladas prontas pra consumo apresentou quantidade de Coliformes totais acima do tolerado pela legislação, porém, a contagem de Coliformes termotolerantes estava conforme.

Embora não existam informações na legislação quanto aos limites de contagens para Coliformes totais, tais análises são realizadas considerando-se que os resultados positivos indicam as más condições higiênicas do local, do produto e o risco da presença de patógenos fecais.

Monteiro (2016) em sua pesquisa com saladas obteve resultados similares aos deste estudo, tendo em vista que, das 37 amostras avaliadas, todas se apresentaram fora dos limites estabelecidos na legislação vigente.

Esses dados se assemelham aos dos pesquisadores Rocha; Soares; Beserra (2014), que realizaram a análise de nove amostras de saladas cruas de diferentes estabelecimentos e constataram a presença de Coliformes totais e termotolerantes em altas quantidades em todas as amostras. 
Em relação às análises de Salmonella spp., dentre as amostras analisadas, apenas a $\mathrm{D}$ apresentou resultado positivo, como demonstrado na tabela 2.

A legislação determina ausência desse agente patógeno em $25 \mathrm{~g}$ de alimento, desta forma, a amostra $\mathrm{D}$ encontra-se em desacordo com o permitido por lei e, inapta para o consumo.

Pertencente à família Enterobacteriaceae, a Salmonella possui forma de bastonetes curtos, gram-negativos não esporogênicos, oxidase negativos e anaeróbias facultativas. Podem se multiplicar em temperaturas a partir de $5^{\circ} \mathrm{C}$, sendo $38^{\circ} \mathrm{C}$ considerada a temperatura ótima de crescimento. Acima de $60^{\circ} \mathrm{C}$ durante 15 a 20 minutos, tem a possibilidade de serem destruídas (SILVA et al., 2007).

Tabela 2. Resultado para presença de Salmonella spp.

\section{AMOSTRAS RESULTADO}

\begin{tabular}{ll}
\hline A & Ausência \\
B & Ausência \\
C & Ausência \\
D & Presença \\
E & Ausência \\
\hline
\end{tabular}

Fonte: Autores (2018)

A Salmonella é considerada um dos principais agentes causadores de DTA em vários países, sendo considerado um risco a saúde pública, devido ao número de morbidades, mortalidade e perda econômica (CAPALONGA, 2014).

De acordo com o Ministério da Saúde (Brasil, 2018), entre o período de 2000 a 2017, 34,1\% dos casos de DTA ocorreram devido à infecção por Salmonella.

Segundo Forsythe (2013), alguns dos alimentos responsáveis pela infecção humana são carnes, ovos, produtos lácteos, frutas e vegetais crus. Os sintomas causados pela Salmonella incluem náuseas, vômitos, dor abdominal, diarreia, febre branda e calafrios. Possui período de incubação de 12 a 36 horas, podendo persistir entre quatro a sete dias. 
O resultado se difere do estudo realizado por Santos et al. (2015), no qual se analisou saladas cruas e cozidas servidas em um restaurante, no estado da Bahia, e em todas amostras analisadas o resultado foi negativo.

Em concordância a esta pesquisa, Oliveira et al. (2011), analisaram amostras de vegetais minimamente processados, na cidade de São Paulo, e obtiveram resultados positivos em duas dessas amostras em relação a presença de Salmonella spp.

A detecção de Staphylococcus coagulase positiva, também prevista na legislação para esse tipo de produto, foi realizada por meio de análises microbiológicas de contagem total em placas e posterior teste de coagulase. No que diz respeito à quantidade desses microrganismos, pode-se dizer que a tolerância para alimentos, de modo geral, é de $10^{3} \mathrm{UFCg}^{-1}$, conforme a ANVISA (BRASIL, 2001). Das amostras analisadas, todas apresentaram contagens de Stapylococcus superiores ao estabelecido pela legislação, entretanto o resultado para o teste de coagulase foi negativo em todas as cepas analisadas (tabela 3).

Tabela 3. Resultado das análises para Staphyloccocus.

\begin{tabular}{clc} 
AMOSTRAS & Sthaphyloccocus & COAGULASE POSITIVA \\
\hline A & No de colônias incontáveis & 0 \\
B & No de colônias incontáveis & 0 \\
C & No de colônias incontáveis & 0 \\
D & No de colônias incontáveis & 0 \\
E & No de colônias incontáveis & 0 \\
\hline
\end{tabular}

Fonte: Autores (2018)

São definidas como cepas Gram positivas, anaeróbias facultativas, não resistentes ao calor. Porém, suas toxinas são altamente resistentes, sendo o motivo da intoxicação de quem as ingere. Além disso, são divididos em duas categorias: coagulase positivos e negativos (SILVA, 2007).

O fato de haver alimentos ou superfície contendo a presença de Staphylococcus spp. pode ser interpretado como indicador de contaminação pelos manipuladores e 
indicativo de ausência de controle higiênico-sanitário nos processos de produção de alimentos e na qualidade de sanitização das superfícies destinadas ao contato com os alimentos (GUIMARÃES e ANDRADE, 2008).

Apesar de não levar a morte e possuir curta duração, seus sintomas são considerados severamente desconfortáveis. Dentre estes, pode-se citar náuseas, vômitos, cólicas, prostração, pressão baixa e queda de temperatura. Geralmente se iniciam entre duas a seis horas após a ingestão e dura em torno de dois dias.

Contagens de Staphyloccocus acima do permitido foram observadas no estudo realizado por Mallet et al. (2017), assim como a presente pesquisa, diferindo, entretanto, no resultado para o teste de coagulase, no qual apresentou-se positiva para uma das nove amostras de saladas cruas coletadas.

No estudo realizado por Souza (2016), duas das 13 amostras, possuíam contagens de Staphyloccocus acima do tolerado, se assemelhando aos resultados deste trabalho e, portanto, consideradas impróprias para o consumo humano.

O resultado encontrado também se assemelha ao obtido pela autora Alves (2015), em que todas as amostras de hortaliças deram positivas em relação à presença dessa bactéria.

As Doenças transmissíveis por alimento (DTAs) ocorrem devido à ingestão de alimento ou água contaminada, ocasionando manifestações digestivas como náuseas, vômitos, diarreia, anorexia, e podendo também afetar outros órgãos como rins, fígado e sistema nervoso (Brasil, 2017).

Segundo o Ministério da Saúde (Brasil, 2017), os surtos de DTA são caracterizados por situações em que duas ou mais pessoas apresentam sintomas e sinais semelhantes, após o consumo de alimentos ou água da mesma origem. Entre os principais transmissores estão bactérias, vírus, toxinas, parasitas e substâncias tóxicas.

Para realizar o monitoramento dos ocorridos, foi criado o Sistema Nacional de Vigilância Epidemiológica das Doenças Transmitidas por Alimentos (VE-DTA), que possui como princípios o controle, a intersetorialidade, prevenção e gestão (BRASIL, 2016).

Há uma grande dificuldade em precisar a dimensão do problema, pois muitos casos de DTAs não são registrados, podendo associar a causa à inconsideração dos sintomas iniciais, fazendo com que a vítima não procure auxílio médico. Ou mesmo pelo 
fato desses sintomas serem parecidos com de outras doenças, e ainda, devido ao tempo de incubação de alguns agentes, tornando difícil a assimilação do alimento ingerido com o diagnóstico (CAPUANO et al, 2008).

Com base nos dados do Ministério da Saúde (2018), na figura 1, podem-se observar os principais alimentos acusados em surtos de DTAs no Brasil, no período de 2000 a 2017.

De acordo com dados da Organização Mundial da Saúde - OMS, no ano de 2010 as DTAs foram responsáveis por 351 mil óbitos no mundo. No Brasil, segundo o Sistema de Informação de Agravos de Notificação - Sinan (2016), entre 2007 e 2016, houve mais de 6.000 surtos, 118.000 doentes e 109 óbitos, sendo em sua maioria homens, entre 20 a 49 anos, no estado do sudeste (43,8\%).

Figura 1. Alimentos acusados como causadores de surtos de DTAs no período de 2000 a 2017, no Brasil.

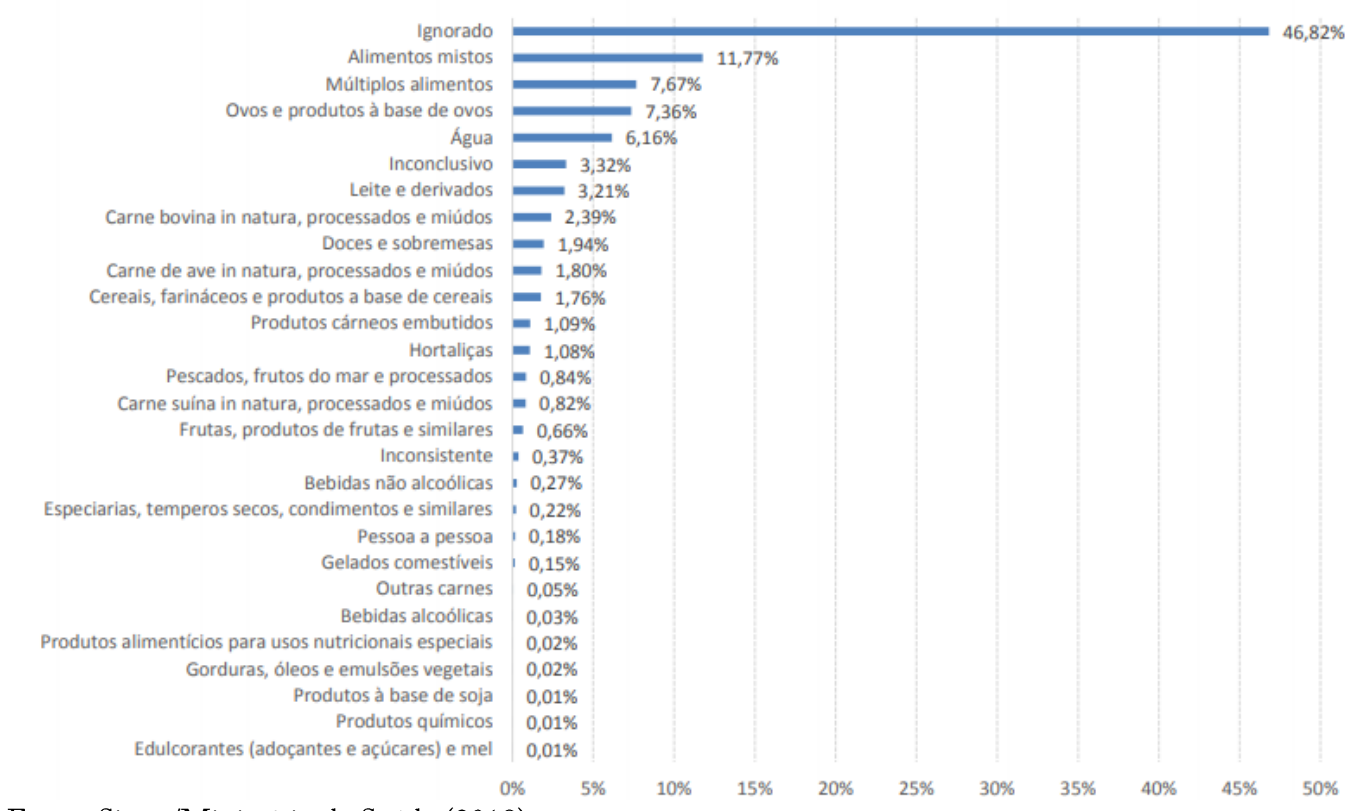

Fonte: Sinan/Ministério da Saúde (2018)

Para Bertolino (2010), a segurança dos alimentos ocorre quando o produto não oferece riscos, de qualquer natureza, à saúde do consumidor. Devem-se levar em consideração as características físico-químicas, microbiológicas e sensoriais desses alimentos, se atentando aos processos de produção, transporte e armazenamento.

A fim de aumentar a segurança dos alimentos para a população brasileira, a Agência Nacional de Vigilância Sanitária (ANVISA)/ Ministério da Saúde, criou a 
RDC no 216/019 de setembro de 2004, na qual é estabelecido o Regulamento Técnico sobre Boas Práticas para Serviços de Alimentação.

A implantação de um Manual de Boas Práticas em estabelecimento produtores de alimentos é fundamental para a produção e comercialização de alimentos saudáveis e que não apresentem riscos de contaminação à saúde dos consumidores. Dessa forma, previnem-se os riscos, atingindo um alto padrão de qualidade dos alimentos. Sendo seu principal objetivo a garantia da integridade do alimento e a saúde do consumidor (NASCIMENTO; BARBOSA, 2007).

\section{Considerações Finais}

Com o desenvolvimento deste estudo, observou-se que os estabelecimentos comerciais estão fornecendo saladas de pote com contagens elevadas de microrganismos, podendo comprometer a saúde do consumidor. Esses resultados podem ser indicativos de contaminação pelos manipuladores e de ausência de controle higiênico-sanitário dos processos de produção das saladas.

Conclui-se que os estabelecimentos pesquisados na cidade de Volta Redonda (RJ) precisam melhorar as condições higiênicas sanitárias das saladas em pote que comercializam, uma vez que surtos causados por microrganismos podem causar doenças graves e levar os indivíduos a morte.

\section{Referências}

ALVES, A. R. D. F. Doenças alimentares de origem bacteriana. Cidade do Porto. 2012. 87 f. Dissertação (Mestrado em Ciências Farmacêuticas) - Faculdade Ciências da Saúde. Universidade Fernando Pessoa, 2012.

ALVES, T. S. Estudo dos indicadores de qualidade microbiológica de hortaliças em dois restaurantes self-service do Distrito Federal. Brasília-DF, 2015.

BERTOLINO, M. T. Gerenciamento da qualidade na indústria alimentícia: ênfase na segurança dos alimentos. Artmed: Porto Alegre, 2010. 
BRASIL. Ministério da Saúde. Agencia Nacional de Vigilância Sanitária. Resolução no 12, de 02 de janeiro de 2001. Regulamento técnico sobre os padrões microbiológicos para alimento. Disponível em: <http://www.anvisa.gov.br/legis/resol/12_01rdc.htm>. Acesso em: 26 de fev. 2018.

BRASIL. Ministério da Saúde. Doenças transmitidas por alimentos. 2017. Disponível em: <http://portalms.saude.gov.br/saude-de-a-z/doencas-transmitidas-por-alimentos>. Acesso em: 08 abr. 2018.

BRASIL. Ministério da Saúde. Guia alimentar para a população brasileira. Brasília, DF, 2014. 2ed. Disponível em:

<http://bvsms.saude.gov.br/bvs/publicacoes/guia_alimentar_populacao_brasileira_2ed.p df>. Acesso em: 23 fev. 2018.

BRASIL. Ministério da Saúde. Manual Técnico de Diagnóstico Laboratorial da Salmonella spp.: Diagnóstico Laboratorial do Gênero Salmonella. Brasília, DF, 2011.

BRASIL. Ministério da Saúde. Surtos de Doenças Transmitidas por Alimentos no Brasil. Brasília, DF, 2018. Disponível em:

<http://portalarquivos2.saude.gov.br/images/pdf/2018/abril/02/Apresentacao-SurtosDTA-Marco-2018.pdf>. Acesso em: 30 de maio 2018.

BRASIL. Ministério da Saúde. Surtos de Doenças Transmitidas por Alimentos no Brasil. Brasília, DF, 2016. Disponível em: <http://portalarquivos2.saude.gov.br/images/pdf/2016/junho/Apresentacao-SurtosDTA-Marco-2016.pdf $>$. Acesso em: 30 de maio 2018.

\section{CAPALONGA, R. Estudo das características Fenotípicas e Genotípicas das} Salmonellas enteretidis envolvidas em surtos alimentares no estado do Rio Grande do Sul no período de 2007 a 2013. 2014. Dissertação (Mestrado) - Universidade Federal do Rio Grande do Sul, 2014.

CAPUANO, D. M. et al. Enteroparasitoses em manipuladores de alimentos do município de Ribeirão Preto - SP, Brasil, 2000. Revista Brasileira de Epidemiologia, São Paulo, v.11, n.4, p.687-695, dez. 2008. Disponível em: $<$ http://www.scielo.br/scielo.php?script=sci_arttext\&pid=S1415790X2008000400015\&1 ng=en\&nrm=iso >. Acesso em: 08 abr. 2018. 
FAGIANI, M. A. B. et al, Avaliação microbiológica e parasitológica de produtos minimamente processados no município de Presidente Prudente - SP. Colloquium Viate, v.9, n.2, p. 17-21, 2017.

FORSYTHE, S. J. Microbiologia da segurança dos alimentos. 2 ed. Porto Alegre: Artmed, 2013. 607p.

FRODER, H. et al. Minimally processed vegetable salads: Microbial quality evaluation. Journal of Food Protection. V. 70, n. 5, 2007, p.1277-1280. Disponível em: $<$ http://jfoodprotection.org/doi/pdf/10.4315/0362-028X-70.5.1277? code=fopr-site >. Acesso em: 26 fev. 2018.

GUIMARÃES, K. A. S.; ANDRADE, A. S. Contaminação de produtos lácteos por Staphylococcus aureus: revisão bibliográfica. Revista Higiene Alimentar, São Paulo, v.22, n.163, p.56-62, 2008.

MACIEL, S. E. S. et al. Unidades de alimentação e nutrição: Aplicação de check - list e avaliação microbiológica. Revista Brasileira de Higiene e Sanidade Animal, Sergipe, v.11, n. 4, p. 399-415, 2017.

MALLET, A. C. T. et al. Avaliação microbiológica de saladas cruas servidas em restaurantes do tipo self-service do município de Volta Redonda (RJ). Cadernos UniFOA, Volta Redonda, n. 34, p. 89-96, ago. 2017.

MOTEIRO, S. E. A. Avaliação da qualidade microbiológica de saladas prontas para consumo comercializadas na região de Lisboa. 2016. Dissertação (Mestrado) Faculdade de Ciências e Tecnologia, Universidade Nova de Lisboa, 2016.

NASCIMENTO, G.A.; BARBOSA, J.S. BPF - Boas Práticas de Fabricação: uma revisão. Revista Higiene Alimentar, São Paulo, v.21, n.148, p.24-30, 2007.

OLIVEIRA, M. A. et al. Microbiological quality of ready-to-eat minimally processed vegetables consumed in Brazil. Food Control, v. 22, p. 1400-1403, 2011.

PAULA, N. R. F. Qualidade de saladas prontas para consumo coletadas em bufês de serviços de alimentação. Lavras: UFLA, 2010. 137p. 
ROCHA, A. N. F; SOARES, R. P; BESERRA, M. L. S. Análise microbiológica de saladas cruas em restaurantes de Teresina-PI. Revista Interdisciplinar, Teresina, v. 7, n.2, p.11-17, abr. mai. jun. 2014.

SANTOS, M. S. Risco microbiológico no consumo de saladas cruas e cozidas servidas em restaurantes self-service em Cruz das Almas, Bahia, Brasil. Magistra, BA, v. 27, n.2, p. 245-252, Abr./Jun 2015.

SILVA, N. et al. Manual de métodos de análise microbiológica de alimentos. 3 ed. São Paulo: Varela, 2007. 536p.

SILVA, P. R. Uma abordagem sobre o mercado de hortaliças minimamente processadas. Informações Econômicas, São Paulo, v.38, n.4, abr. 2008.

SOUZA, R. A. M. Mercado para produtos minimamente processados. Informações Econômicas, São Paulo, v.31, n.3, p. 7-18, mar. 2001.

SOUZA, Y. J. B. Avaliação da qualidade microbiológica de vegetais minimamente processados comercializados em Brasília-df. Brasília-DF, 2016.

TRESSELER, J. F. M. et al. Avaliação da qualidade microbiológica de hortaliças minimamente processadas. Ciênc. Agrotec, Lavras, v. 33, p. 1722-1727, 2009.

WORLD HEALTH ORGANIZATION. WHO estimates of the globalburden of foodborne diseases: foodborne disease burden epi-demiology reference group 20072015. Genebra: World Health Organization, 2015. 